\title{
FACTORS AFFECTING VISUAL OUTCOME IN CHILDREN FOLLOWING UNIOCULAR TRAUMATIC CATARACT
}

\author{
A. J. CHURCHILL, B. A. NOBLE, D. E. ETCHELLS and N. J. GEORGE \\ Leeds
}

\begin{abstract}
SUMMARY
The correction of paediatric traumatic aphakia remains a controversial topic. This study examines retrospectively the visual outcome in 32 children with uniocular traumatic cataracts. Fifteen received intraocular lens implants following lensectomy, and 17 received aphakic contact lenses. Age range was $2-14 \frac{1}{2}$ years at the time of injury. The maximum follow-up time was 13 years. Twenty-four children obtained a good visual result (6/5 to 6/18). These were equally divided between those receiving intraocular lens implants and those with contact lenses. Factors adversely affecting visual outcome are discussed. These include complex trauma, delay in referral for lensectomy, inadequate postoperative correction of aphakia, contact lens difficulties and problems with occlusion therapy. Although aphakic correction with intraocular lens implants may require several subsequent surgical procedures such as capsulotomy, we advise early lensectomy and intraocular lens implantation where possible, particularly in young children with traumatic cataracts. This eliminates contact-lens-associated problems and maximises the chance of good visual outcome and retention of stereoscopic vision.
\end{abstract}

There are uncertainties about the biological tolerance of intraocular lenses in young eyes. Some ophthalmologists prefer to reserve their use for older children whereas others do not believe they should be used at all. ${ }^{1}$ The method of aphakic correction following the extraction of traumatic cataracts remains controversial. Complications previously associated with intraocular lens implantation have been minimised with the use of newer lens designs. Those in favour of this technique believe there are now more problems arising from contact lens wear, particularly in children from low socioeconomic classes. ${ }^{2,3}$

Correspondence to: Mr Bruce Noble, Ophthalmology Department, Clarendon Wing, The General Infirmary at Leeds, Belmont Grove, Leeds, West Yorkshire LS2 9NS, UK.
We performed a retrospective study to determine whether any difference existed in the long-term visual outcome in 32 children receiving either an intraocular lens (IOL) implant or an aphakic contact lens (CL) following lensectomy for a uniocular traumatic cataract.

\section{SUBJECTS AND METHODS}

All children admitted to Leeds General Infirmary between 1979 and 1992 with a uniocular traumatic cataract were included in the study and their medical records reviewed retrospectively. Each patient was sent a letter inviting them to attend the eye clinic for examination (only a minority were still attending for routine follow-up). Visual acuity and stereopsis were measured in the 16 who attended (the latter using a combination of the Wirt fly, TNO and Frisby tests). Four children attended Bradford University to have specular microscopy performed at a separate visit. Details of age at the time of injury, causative weapon, presenting visual acuity, time to lensectomy and post-operative complications were recorded (Tables I and V). Particular note was made as to whether an IOL or CL was used to correct the aphakia. There were 16 children who were either unable to attend or were uncontactable; in these cases the information was taken from the last visit recorded in the medical records.

Thirty-two children were identified (5 girls and 27 boys). The age range at the time of injury was $2-14 \frac{1}{2}$ years. Follow-up ranged from 2 months to 13 years with a mean of 4.2 years. The patients were divided into two groups. Group I consisted of 14 children who were 7 years or younger at the time of trauma (4 girls, 10 boys). Group II consisted of 18 children who were older than 7 years at the time of trauma (1 girl, 17 boys). The groups were further sub-divided according to whether an IOL or CL was used for the aphakic correction (Table II).

In 19 cases the nature of the trauma was 
Table I. Patient information

\begin{tabular}{|c|c|c|c|c|c|c|c|c|c|}
\hline $\begin{array}{l}\text { Case } \\
\text { no. }\end{array}$ & $\begin{array}{c}\text { Age at } \\
\text { injury (yr) }\end{array}$ & $\begin{array}{l}\text { Presenting } \\
\text { VA }\end{array}$ & $\begin{array}{l}\text { Causative } \\
\text { weapon }\end{array}$ & $\begin{array}{l}\text { Time to } \\
\text { lensectomy } \\
\text { (weeks) }\end{array}$ & Aphakic correction & $\begin{array}{l}\text { Age at final } \\
\text { VA (yr) }\end{array}$ & Final VA & $\begin{array}{l}\text { Stereopsis } \\
(+ \text { or }-)\end{array}$ & $\begin{array}{c}\text { Total no. } \\
\text { of ops. }\end{array}$ \\
\hline \multicolumn{10}{|c|}{ Group I (7 years or younger) } \\
\hline 1 & 2.8 & $?$ & Dart & 1 & PC IOL 25.0D & 4.6 & $6 / 6$ & + & 3 \\
\hline 2 & 6 & $\mathrm{HM}$ & Badge pin & 1.5 & PC IOL 22.0D & 13 & $6 / 9$ & + & 4 \\
\hline 3 & 5 & $?$ & Twig & $<0.5$ & CL (2 PC IOL 22.0D) & 11.8 & $6 / 12$ & - & 6 \\
\hline 4 & 2 & $?$ & Window sill & 2 & $\mathrm{CL}$ & 4 & $6 / 12$ & $?$ & 2 \\
\hline 5 & 6 & $6 / 36$ & Stone & 5 & $\mathrm{CL}$ & 18 & $6 / 12$ & - & 3 \\
\hline 6 & 2 & $?$ & Cupboard door & 28 & PC IOL 20.5D & 13 & $6 / 18$ & + & 17 \\
\hline 7 & 5 & $\mathrm{CF}$ & Twig & 6 & CL & 9.2 & $6 / 18$ & - & 3 \\
\hline 8 & 4.5 & PL & Plastic stick & 6 & PC IOL 22.0D & 10.5 & $6 / 24$ & $?$ & 4 \\
\hline 9 & 3 & PL & Nail & 44 & $\mathrm{CL}$ & 4.1 & $<6 / 60$ & - & 3 \\
\hline 10 & 4 & PL & Screw & 44 & AC IOL & 9 & $2 / 60$ & - & 5 \\
\hline 11 & 3 & PL & Unknown & 3 & $\mathrm{CL}$ & 15.3 & $1 / 60$ & - & 4 \\
\hline 12 & 5 & $\mathrm{HM}$ & Scissors & 1 & CL (2 IOL 19.0D) & 10.7 & $1 / 60$ & - & 2 \\
\hline 13 & 6 & $\mathrm{CF}$ & Knife & 2 & PC IOL 21.0D & 13.8 & NPL & - & 6 \\
\hline 14 & 7 & PL & Chisel & 4 & $\mathrm{CL}$ & 7.5 & $\mathrm{AE}$ & - & 5 \\
\hline \multicolumn{10}{|c|}{ Group II (older than 7 years) } \\
\hline 15 & 14 & HM & Plastic sword & 6 & PC IOL & 15.2 & $6 / 5$ & $?$ & 3 \\
\hline 16 & 10 & HM & Dart & $<0.5$ & CL & 11.8 & $6 / 5$ & + & 4 \\
\hline 17 & 14 & $6 / 36$ & Blowdart & 8 & $\mathrm{CL}$ & 14.2 & $6 / 5$ & ? & 1 \\
\hline 18 & 14 & PL & Airgun pellet & 26 & PC IOL 23.5D & 15 & $6 / 6$ & + & 1 \\
\hline 19 & 10 & HM & Twig & $<0.5$ & $\mathrm{CL}$ & 19.5 & $6 / 6$ & + & 3 \\
\hline 20 & 12 & $\mathrm{CF}$ & Brick & 1.5 & AC IOL & 14.8 & $6 / 7.5$ & $?$ & 1 \\
\hline 21 & 11 & $\mathrm{CF}$ & Scissors & $<0.5$ & PC IOL & 11.3 & $6 / 9+$ & $?$ & 3 \\
\hline 22 & 12.8 & HM & Rubber band & 26 & PC IOL 25.0D & 13.5 & $6 / 9+$ & + & 1 \\
\hline 23 & 14 & $6 / 24$ & Stone & 32 & PC IOL & 17 & $6 / 9$ & + & 1 \\
\hline 24 & 8 & $6 / 24$ & Knife & 156 & PC IOL 19.0D & 9.1 & $6 / 9$ & $?$ & 3 \\
\hline 25 & 8 & $\mathrm{CF}$ & Scissors & $<0.5$ & $\mathrm{CL}$ & 9.5 & $6 / 9$ & + & 3 \\
\hline 26 & 9 & CF & Drawing pin & 0.5 & CL & 22 & $6 / 9$ & - & 3 \\
\hline 27 & 10 & $\dot{\mathrm{CF}}$ & Dart & 6 & $\mathrm{CL}$ & 13 & $6 / 9$ & + & 2 \\
\hline 28 & 11 & $?$ & Unknown & 208 & CL & 16 & $6 / 9$ & $?$ & 2 \\
\hline 29 & 12 & HM & Stone & 34 & PC IOL & 13.3 & $6 / 18$ & $?$ & 1 \\
\hline 30 & 14 & $\mathrm{HM}$ & Table edge & 12 & PC IOL 22.0D & 14.8 & $6 / 18$ & $?$ & 2 \\
\hline 31 & 8 & PL & Biro & 24 & $\mathrm{CL}$ & 8.8 & $6 / 18$ & $?$ & 1 \\
\hline 32 & 10 & $\mathrm{CF}$ & Toy helicopter & 260 & $\mathrm{CL}$ & 10.6 & $\mathrm{CF}$ & - & 1 \\
\hline
\end{tabular}

VA, visual acuity; ops., operations; AC, anterior chamber; PC, posterior chamber; CL, contact lens; IOL, intraocular lens; D, dioptres; $\mathrm{CF}$, counting fingers; HM, hand movement; PL, perception of light; NPL, no perception of light; AE, artificial eye.

penetrating and in 13 cases it was blunt. Thirteen cases involved posterior segment trauma requiring operative intervention ranging from cryotherapy to vitreotomy and retinal detachment surgery (Table III). These cases were fairly evenly split between the two age groups. The time lapse between initial trauma and lensectomy ranged from a few hours to 5 years.

The majority of the operating was performed by one of the authors (B.A.N.). Following primary repair bimanual ocutome techniques were usually used to remove soft lens matter, anterior capsule and scar tissue. Vitrectomy was limited and only performed where damage to the posterior capsule had been observed. The posterior capsule was retained wherever possible to provide support for a posterior chamber lens implant (13 eyes). If there was insufficient capsule remaining an anterior chamber lens of multiflex design was used ( 2 eyes). All children had preoperative mydriatics and all received post-operative topical and systemic antibiotics, topical steroids and mydriatics.

Lens implantation was performed in 15 eyes at the time of lensectomy and a further 2 eyes received secondary implants at a later date because of CL intolerance. Several types of IOL were used including three-piece designs and disc implants. The lens power was calculated from keratometer readings and A-scan axial length measurements where possible, although in the majority of earlier cases a 'standard' adult power lens was used. The IOLs used ranged in power from +19.0 to +25.0 dioptres. Occlusion therapy was started as soon as possible after surgery in the younger group. Reading and distance corrections were prescribed as bifocals to correct any residual refractive error in both groups. Postoperative complications and further surgical procedures were recorded. The latest recorded acuity was taken as the 'final visual acuity' and categorised as 'good' if the acuity ranged from $6 / 5$ to $6 / 18$ or 'poor' if less than 6/18. Presence or absence of stereopsis

Table II. Patient subgroups according to age and type of operation

\begin{tabular}{lcc}
\hline & \multicolumn{2}{c}{ Aphakic correction } \\
\cline { 2 - 3 } Age at injury & IOL & CL \\
\hline Group I $<7$ years $(n=14)$ & 6 & 8 \\
Group $>7$ years $(n=18)$ & 9 & 9 \\
\hline
\end{tabular}


Table III. Severity of injury versus visual outcome

\begin{tabular}{|c|c|c|c|c|c|c|c|}
\hline $\begin{array}{l}\text { Case } \\
\text { no. }\end{array}$ & $\begin{array}{c}\text { Grade of } \\
\text { trauma }\end{array}$ & Final VA & Explanation for poor VA & Case no. & $\begin{array}{c}\text { Grade or } \\
\text { trauma }\end{array}$ & Final VA & Explanation for poor VA \\
\hline 1 & $\mathrm{~b}$ & $6 / 6$ & & 17 & $\mathrm{a}$ & $6 / 5$ & \\
\hline 2 & a & $6 / 9$ & & 18 & a & $6 / 6$ & \\
\hline 3 & b & $6 / 12$ & & 19 & a & $6 / 6$ & \\
\hline 4 & b & $6 / 12$ & & 20 & a & $6 / 7.5$ & \\
\hline 5 & $\mathrm{a}$ & $6 / 12$ & & 21 & b & $6 / 9+$ & \\
\hline 6 & a & $6 / 18$ & & 22 & a & $6 / 9+$ & \\
\hline 7 & a & $6 / 18$ & & 23 & a & $6 / 9$ & \\
\hline 8 & a & $6 / 24$ & Occlusion problems & 24 & $\mathrm{a}$ & $6 / 9$ & \\
\hline 9 & a & $<6 / 60$ & Late referral & 25 & a & $6 / 9$ & \\
\hline 10 & a & $2 / 60$ & Late referral & 26 & a & $6 / 9$ & \\
\hline 11 & a & $1 / 60$ & CL problems & 27 & a & $6 / 9$ & \\
\hline 12 & b & $1 / 60$ & CL problems & 28 & b & $6 / 9$ & \\
\hline 13 & b & NPL & Complex retinal injury & 29 & b & $6 / 18$ & \\
\hline 14 & b & $\mathrm{AE}$ & Complex retinal injury & 30 & a & $6 / 18$ & \\
\hline 15 & $\mathrm{~b}$ & $6 / 5$ & & 31 & b & $6 / 18$ & \\
\hline 16 & b & $6 / 5$ & & 32 & b & $\mathrm{CF}$ & Complex retinal injury \\
\hline
\end{tabular}

Grade of trauma: a, cornea-lens only; b, iris, vitreous and retinal involvement.

was recorded. Children with a poor visual outcome were further investigated and an explanation sought. Those factors adversely affecting long-term visual acuity were identified.

Specular microscopy was carried out in 4 children (cases 2,11, 13 and 26) using a Nikon AS-1 noncontact slit lamp. Ektachrome 200 was used to produce a series of images of thin strips of the endothelium. Samples of these were re-photographed through a macroscope onto XP-1 monochrome film for projection and manual cell counting.

\section{RESULTS}

\section{Visual Acuities}

Final acuities are shown in Table I. Half of the children (7) in group I achieved a good result, 3 with primary IOL implants and 4 with CLs (one later required a secondary IOL). In group II, 17 children achieved a good result; 9 had IOL implants and 8 were fitted with CLs. A total of 8 children had a poor result (visual acuities less than 6/18), 7 of whom were from the younger age group. Two of these children were very late referrals (cases 9 and 10), both were under 5 years old and, on admission, could only perceive light; surgery was performed for reasons of comfort and appearance. Three children had complex trauma involving the mid and posterior segments (cases 13,14 and 32) and had unsuccessful retinal detachment surgery; one later required enucleation for a painful blind eye. Two of the remaining 3 children with a poor result were completely intolerant of CLs whilst the third totally refused occlusion treatment. This last group were poor attenders at the clinic and consequently developed dense amblyopia. A summary of the adverse factors affecting visual outcome following uniocular trauma is shown in Fig. 1.

\section{Stereopsis}

Seven from group 1 and 9 from group II attended for measurement of stereopsis. Information for a further 5 children was obtained from the medical notes.

In group I there were 3 children who showed stereoscopic vision. All 3 had IOLs. In group II, 7 children showed stereoscopic vision; 3 had IOLs and 4 wore CLs. There were 2 children who appeared to have lost stereopsis; one had a total retinal detachment and the other had a poor record of CL wear resulting in suppression.

\section{Endothelial Cell Counts}

Specular microscopy was performed on 4 children, but in only 3 were photographs produced of a high enough quality for endothelial cell counts to be accurately compared between the traumatised and non-traumatised eye. Cell counts were taken from the central corneal area in each eye. All 3 had penetrating corneal injuries of a similar nature (case 13 developed a complex retinal detachment following lensectomy resulting in the poor visual acuity). Both children receiving IOLs maintained high endothelial cell counts. The results are shown in Table IV.

\section{Surgical Procedures}

The total number of surgical/laser procedures for each child is shown in Table I. For 8 of 32 children only one procedure was necessary (lensectomy with or without corneal repair). The majority required further general anaesthesia; this was most commonly for removal of corneal sutures, posterior capsulotomy, and accurate refraction. Children with implants

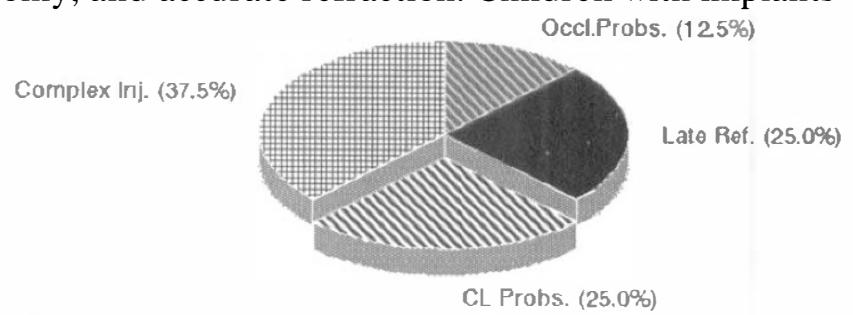

Fìg. 1: Fäctors accounting för poor vision. 
Table IV. Endothelial cell counts

\begin{tabular}{rcccccc}
\hline & & \multicolumn{2}{c}{ Endothelial cell count $\left(/ \mathrm{mm}^{2}\right)$} & & \\
\cline { 3 - 4 } Case no. & Years since trauma & Traumatised eye & Healthy eye & & \% cell loss & Aphakic correction \\
\hline 11 & 12 & 1861 & 3008 & 38 & CL \\
2 & 7 & 2560 & 3246 & 21 & IOL \\
13 & 8 & 2294 & 3311 & 31 & IOL \\
\hline
\end{tabular}

had an average of four surgical procedures (which included lens repositioning in one case), compared with 3 in those who had lensectomy alone.

\section{Post-operative Complications}

Post-operative complications were more common in those eyes with complex trauma and included retinal detachment, and endophthalmitis (Table V). Four children had gross corneal scarring necessitating grafting and one child had a painful blind eye which was enucleated. Intraocular lens displacement occurred in 3 children (cases 2, 8 and 15) but only one required repositioning (case 15). Two children complained of diplopia and 8 developed varying degrees of strabismus.

\section{DISCUSSION}

In $1921 \mathrm{Juler}^{4}$ published the visual acuities in a group of children following traumatic cataract and demonstrated the concept of 'amblyopia through disuse'. Now it is universally accepted that early and adequate correction of aphakia is crucial to a good visual outcome. This has been achieved in a variety of ways over the past 70 years. Spectacles were the first method to be tried but gave disappointing results. ${ }^{5}$ Epikeratophakia has been used with success in the United States but has not proved to be a popular option in the UK.$^{6,7}$ The main problems are photophobia and the slow recovery of clarity to the tissue lens (up to 2 years). ${ }^{8}$ For surgeons in the UK the choice effectively lies between a CL or IOL implantation. Both methods of correction have their own advantages and associated problems. The purpose of this study was to determine whether there was any clinically significant difference in the long-term visual outcome between the two.

The fitting of CLs in small children with severely injured eyes poses both medical and social challenges. The eyes are irritable and water profusely. Parents are left to handle the CLs and many find it difficult to cope. Those in our study complained of

Table V. Post-operative complications

\begin{tabular}{lcc}
\hline Complication & Group I & Group II \\
\hline Retinal detachment & 2 & 1 \\
Corneal grafting & 3 & 1 \\
Endophthalmitis & 0 & 2 \\
Strabismus & 5 & 3 \\
Enucleation & 1 & 0 \\
Diplopia & 0 & 2 \\
Displaced IOL & 2 & 1 \\
\hline
\end{tabular}

the difficulties involved in handling the CLs, stating that it took one parent to hold the child still whilst the other attempted to remove or replace the CL. In many instances there was only one parent remaining in the family unit struggling to manage these difficulties alone.

It is not always possible to fit a CL to a traumatised cornea due to the irregular surface contours (Fig. 2), and even after successful fitting there may be later complications such as corneal vascularisation and giant papillary conjunctivitis. Advances in $\mathrm{CL}$ manufacture have enabled the use of extended wear aphakic lenses, considerably easing what previously had to be a daily battle between parent and child to remove and replace CLs after cleaning. ${ }^{9}$ Contact lens losses are frequent and replacement costs are high. In our study an average of six CLs were required per child during the first 18 months post-operatively. Unscheduled attendances at the clinic were common, adding further strain to both parents and ophthalmologist. CL failure is said to be common for a variety of reasons and Hiles ${ }^{10}$ reported a failure rate of at least $52 \%$ in an 18 year follow-up study of children with traumatic aphakia. However, of the 17 children in our study receiving CLs only 3 in the younger group completely abandoned them (cases 3, 11 and 12). Case 11 failed to attend either $\mathrm{CL}$ or orthoptic follow-up and became profoundly amblyopic. Case 12, who had a complex injury involving cornea, lens and vitreous, also failed follow-up, developed amblyopia and despite secondary lens implantation achieved a visual acuity of only $1 / 60$. Case 3 , who had a similar injury to case 12 , was identified as having problems early and achieved a sustained visual acuity of $6 / 12$ following posterior chamber secondary lens implantation.

A Canadian study in 1989 showed that when binocular function was disrupted for $2 \frac{1}{2}$ years or more by uncorrected aphakia in children over the age of 10 years intractable diplopia resulted in all cases. ${ }^{11}$ In our study we identified 2 children who, in their teens, despite achieving good visual acuities, discarded their CLs citing the effort and cost of their maintenance as the main contributory factors. They both now demonstrate diplopia when corrected and prefer to remain unilaterally aphakic. These 2 cases could be classed as 'late' CL failure. However, CLs give excellent results if worn well; 12 of the 17 children $(71 \%)$ we fitted with CLs achieved final visual acuities between $6 / 5$ and 6/18. 


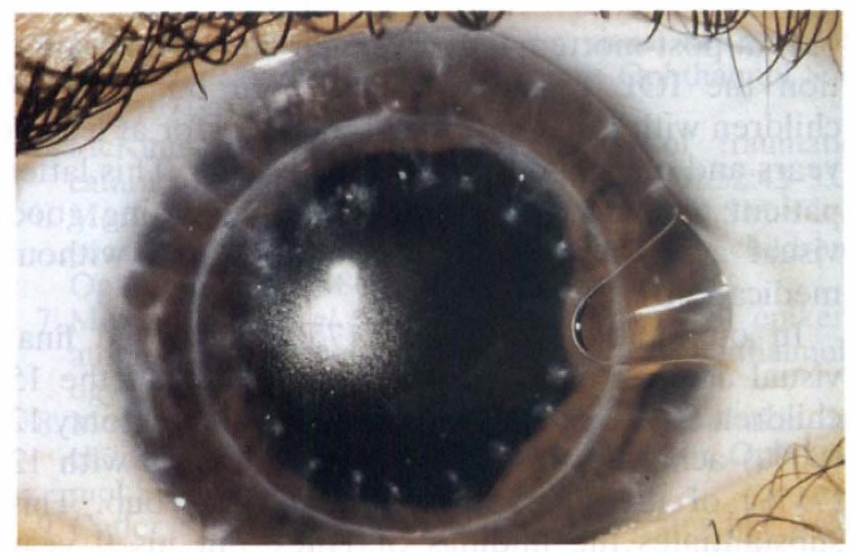

Fig. 2. Contact lens problems in case 4.

Intraocular lens implantation in children is difficult and not technically possible in every case, although microsurgical advances have considerably widened the repertoire of anatomical and pathological situations in which lens implantation can be attempted. In our study the decision as to whether an implant was used was based on the expertise of the surgeon, availability of viscoelastic materials and suitability of implants. In the more recent cases, as our experience in managing these young traumatised eyes developed, IOL implantation became more popular, particularly where the social circumstances made CL failure a high probability. It should be stressed, however, that the final choice of aphakic correction was decided only after a full discussion with the parents and child (if old enough).

Choyce $^{12}$ was the first to describe placing an anterior chamber IOL in a child in 1958. Many different types of lens implant have been tried since but the most commonly used implant today is the one-piece PMMA posterior chamber design (Fig. 3). This is ideally placed in the capsular bag for support. If the posterior capsule is severely disputed when it is possible to use the anterior capsule for support and

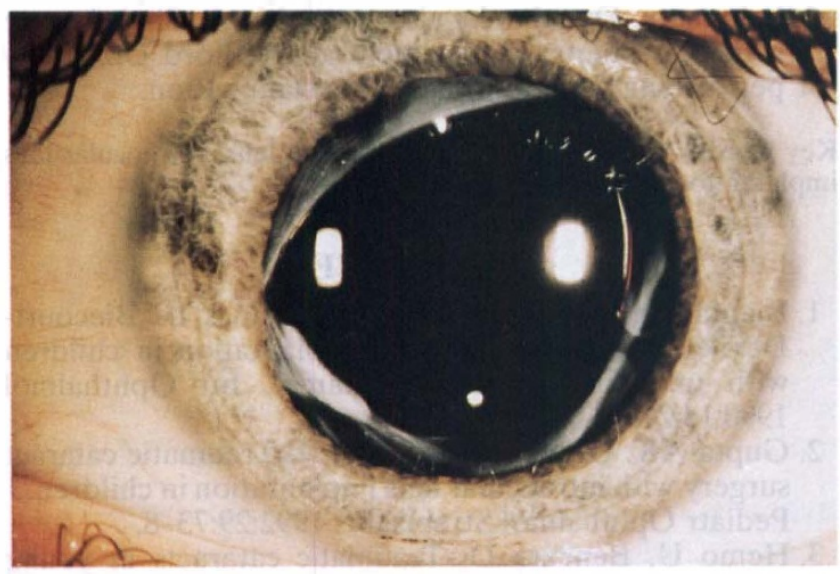

Fig. 3. Well-positioned one-piece PMMA posterior chamber IOL following instillation of a mydriatic in case 18. place the posterior lens implant in the ciliary sulcus with good result, although this necessitates some form of central capsulotomy either at the time of surgery or afterwards with the Nd:YAG laser. In our study if there was sufficient capsule remaining for either approach we did not attempt to use sutured posterior IOLs but proceeded to anterior chamber lens placement. In traumatised eyes, especially in children, the scar tissue and capsular fibrosis conspire together to displace the IOL. The Prolene loops of the three-piece lenses seem unable to resist these forces and some of these eyes show dramatic slit lamp appearances (Fig. 4). Surprisingly the vision seems to be unaffected. Capsular opacification obscuring the visual axis is frequently seen and most patients required either needling or $\mathrm{Nd}$ :Yag laser capsulotomy.

Endothelial cell loss has been studied by several authors. Slingsby and Forstot ${ }^{13}$ have shown that blunt trauma accounts for 6-7\% endothelial cell loss. This figure appears to be only slightly higher (7-8\%) following corneal penetration. ${ }^{14}$ Roper-Hall and Wilson $^{14}$ found that lensectomy caused further endothelial trauma, increasing the total cell loss to approximately $36 \%$, but lens implantation had a negligible effect provided there was not undue contact between the IOL and the corneal endothelium during surgery. With the use of viscoelastics and posterior chamber implants endothelial cell loss can be minimised. In our study the traumatised eyes lost between $21 \%$ and $38 \%$ of endothelial cells compared with the healthy eyes (Table IV). The largest cell loss occurred in the eye which did not receive an IOL (case 11). Kora et al. ${ }^{16}$ have also demonstrated normal corneal endothelial studies in 8 children receiving posterior chamber IOL implants following removal of traumatic cataracts. All these are small studies but the results are certainly encouraging. Larger numbers, however, would be required before any statistically relevant conclusions could be drawn to be used as an argument either for or against IOL implantation in children.

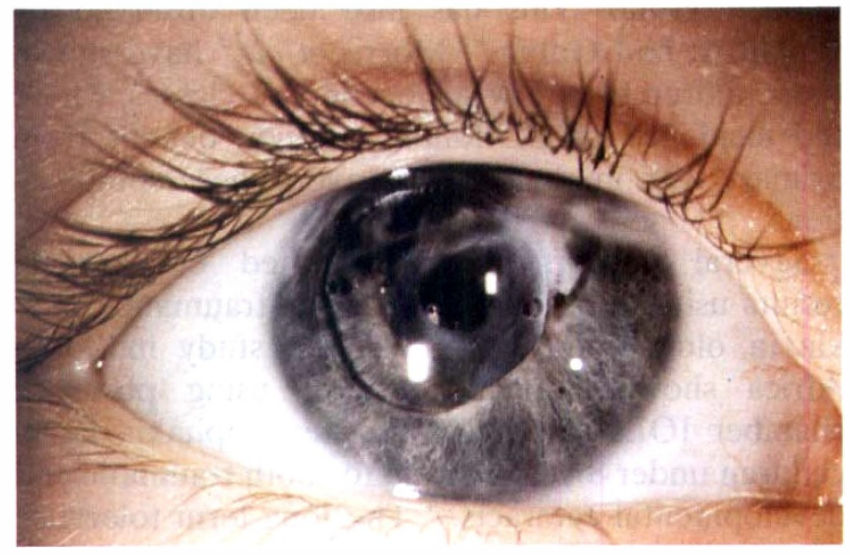

Fig. 4. Displaced IOL in case 8 . 
Tytla et al. ${ }^{17}$ have developed a new method of stereoscopic testing in amblyopic and strabismic patients (TLMB test) who were not able to perform the conventional tests. They demonstrated that 4 children who developed traumatic cataracts before 6 years of age and showed no clinical stereopsis had TLMB test acuities ranging from 225 to 28 arc-sec. It remains to be seen whether this test becomes accepted as a useful method of testing stereopsis in these children. A recent study in Turkey found that the most important factors in achieving near stereopsis (following CL correction of traumatic aphakia) were the time taken to lensectomy and the time interval from this operation to wearing CLs. ${ }^{18}$ In our study we found that the time to lensectomy was not as influential in determining long-term stereopsis as the early and continued correction of aphakia, whether by IOL or CL, in both age groups and the strict adherence to occlusion therapy in the younger group. This is well illustrated by case 12 who, although undergoing lensectomy and aphakic CL correction within a week of trauma, defaulted from follow-up, discarded the CL, abandoned occlusion and, as a result, developed profound amblyopia. In the younger age group none of the children whose aphakia was corrected with CLs showed stereoscopic vision with the clinical tests used, whereas 3 of the children receiving IOLs did demonstrate stereopsis. Although this study is small it does suggest that retention of stereopsis is more likely if the aphakia is corrected by lens implantation.

In our experience children with corneal/lens trauma alone fared considerably better than those with more complex injuries involving the mid or posterior segments. There were 8 children $(25 \%)$ who achieved final visual acuities less than $6 / 18$ and in 5 this outcome was potentially avoidable. Two were very late referrals and already profoundly amblyopic at presentation and 3 had problems with CLs and occlusion. All parents reported some problems with managing occlusion in the younger group, but patching was better tolerated in the implant group. This has also been observed by Binkhorst and Gobin. ${ }^{19}$ Morris et al. ${ }^{20}$ have shown that children from low socioeconomic classes, where the incidence of CL failure is high, benefit from primary IOL implantation to avoid these complications.

Several authors have published encouraging results using IOL implantation for traumatic aphakia in older children ${ }^{2,21-23}$ and a study in South Africa showed the benefits of using posterior chamber IOLs to correct unilateral aphakia in 80 children under 8 years of age for both traumatic and developmental cataracts. ${ }^{24}$ The long-term tolerance of young eyes to lens implants remains uncertain but Reynolds et al. ${ }^{25}$ have demonstrated (in a 16-year- old) at post-mortem that 6 years following implantation the IOL remained inactive. In our study 7 children with IOLs have been followed for at least 5 years and one child (case 6) for 11 years. This latter patient appears clinically stable, maintaining good visual acuity with stereopsis at $6 / 18$ and without medication.

In our study 24 children (75\%) achieved final visual acuities of between $6 / 5$ and 6/18. Of the 15 children receiving IOLs at the time of lensectomy 12 $(80 \%)$ achieved this good result compared with 12 ( $71 \%)$ of the 17 children in the CL group. This substantiates the findings of Hiles $^{26}$ in his 9 year follow-up. The similarity of these visual results gives the impression that the choice of aphakic correction is arbitrary. However, the results do not show the enormous difference in the demands placed on the parents of the children in the two groups $(\mathrm{CL}$ or IOL). For example, the parents of children with implants found occlusion treatment much easier than those with CLs. All parents experienced difficulties in handling CLs and the poor wear record of some teenagers should not be ignored.

The decision about the type of aphakic correction used should be taken by the ophthalmologist in full consultation with the parents. The surgical problems should not be underestimated and it may be neither advisable nor technically possible to implant a lens as a primary procedure in every case. In the younger age group stimulus deprivation amblyopia is the main risk and follow-up of these children will necessarily require the joint efforts of ophthalmologist, orthoptist and optometrist in supporting the parents in their struggle. The easier it is for the parents the greater the chance of a good visual outcome. Taking these and other factors into account we recommend IOL implantation, where possible, as the first choice of aphakic correction in children of any age following lensectomy for traumatic cataract.

We are grateful to Mr R. M. L. Doran, Mr J. M. Hayward and the late Brian Harcourt for allowing us to report three of their cases. Our thanks also go to Mr A. Shakespeare from the Optometry Department at Bradford University for performing the endothelial cell examination.

Key words: Amblyopia, Children, Contact lens, Intraocular lens implantation, Traumatic cataract.

\section{REFERENCES}

1. Bienfait MF, Pameijer JH, Wildervanck de BiecourtDevilee M. Intraocular lens implantation in children with unilateral traumatic cataract. Int Ophthalmol 1990;14:271-6.

2. Gupta AK, Grover AK, Gurha N. Traumatic cataract surgery with intraocular lens implantation in children. J Pediatr Ophthalmol Strabismus 1992;29:73-8.

3. Hemo U, Benezra D. Traumatic cataracts in young children (correction of aphakia by intraocular lens implantation). Ophthalmic Paediatr Genet 1987;8: 203-7. 
4. Juler F. Amblyopia from disuse: visual acuity after traumatic cataract in children. Trans Ophthalmol Soc UK 1921;41:129-39.

5. McKinna AJ. Results of treatment of traumatic cataract in children. Am J Ophthalmol 1961;52:43-53.

6. Morgan KS, Arffa RC, Marvelli TL, Verity SM. Five year follow-up of epikeratophakia in children. Ophthalmology 1986;93:423-32.

7. Morgan KS, et al. The nationwide study of epikeratophakia for aphakia in older children. Ophthalmology 1988;95:526-32.

8. Morgan KS, Stephenson GS. Epikeratophakia in children with corneal lacerations. J Pediatr Ophthalmol Strabismus 1985;22:105-8.

9. Cutler SI, Nelson LB, Calhoun JH. Extended wear contact lenses in paediatric aphakia. J Pediatr Ophthalmol Strabismus 1985;22:86-91.

10. Hiles DA. Corneal lacerations, traumatic cataract and the optical correction of aphakia. Am Orthoptic J 1985;35:145-50.

11. Pratt-Johnson JA, Tillson G. Intractable diplopia after vision restoration in unilateral cataract. Am J Ophthalmol 1989;107:23-6.

12. Choyce DP. Correction of uni-ocular aphakia by means of anterior chamber acrylic implants. Trans Ophthalmol Soc UK 1958;78:459-70.

13. Slingsby JG, Fostot SL. Effect of blunt trauma on the corneal endothelium. Arch Ophthalmol 1981;99: 1041-3.

14. Roper-Hall MJ, Wilson, RS, Thompson SM. Changes in endothelial cell density following accidental trauma. Br J Ophthalmol 1982;66:518-9.

15. Roper-Hall MJ, Wilson RS. Reduction in endothelial cell density following cataract extraction and intraocular lens implantation. Br J Ophthalmol 1982;66:5167.

16. Kora Y, Inatomi M, Fukado Y, Marumori M, Yaguchi
S. Long-term study of children with implanted intraocular lenses. J Cataract Refract Surg 1992; 18:485-8.

17. Tytla ME, Lewis TL, Maurer D, Brent HP. Stereopsis after congenital cataract. Invest Ophthalmol Vis Sci 1993;34:1767-73.

18. Kozer Bilgin L, Pakter S, Sezen F, Tugal Tutkun I. Binocular vision regained after monocular traumatic aphakia by wearing contact lenses. Eur J Ophthalmol 1992;2:86-90.

19. Binkhorst CD, Gobin MH. Treatment of congenital and juvenile cataract with intraocular lens implants (pseudophakoi). Br J Ophthalmol 1970;54:759-65.

20. Morris JA, Taylor D, Rogers JE, et al. Contact lens treatment of aphakic infants and children. J Br Contact Lens Assoc 1979;2:22-30.

21. Blumenthal M, Yalon M, Triester G. Intraocular lens implantation in traumatic cataract in children. Am Intraocular Implant Soc J 1983;9:40-1.

22. Burke JP, Willshaw HE, Young JDH. Intraocular lens implants for uniocular cataracts in childhood. Br J Ophthalmol 1989;73:860-4.

23. Van Balen ATM. Four years' experience with Binkhorst lens implantation. Am J Ophthalmol 1973; 75:755-63.

24. Dahan E, Salmenson BD. Pseudophakia in children: precautions, technique and feasibility. J Cataract Refract Surg 1990;16:75-82.

25. Reynolds JD, Hiles DA, Johnson BL, Biglan AW. A histopathologic study of bilateral aphakia with a unilateral intraocular lens in a child. Am J Ophthalmol 1982;93:289-93.

26. Hiles DA. Intraocular lens implantation in children with monocular cataracts. Ophthalmology 1984;91: 1231-7. 